\title{
Future of family planning program in Bangladesh: Issues and challenges
}

Ubaidur Rob

Population Council

Md. Noorunnabi Talukder

Population Council

A.K.M. Zafar Ullah Khan

Population Council

Follow this and additional works at: https://knowledgecommons.popcouncil.org/departments_sbsr-rh

Part of the Demography, Population, and Ecology Commons, Family, Life Course, and Society Commons, Gender and Sexuality Commons, International Public Health Commons, Maternal and Child Health Commons, Medicine and Health Commons, and the Women's Health Commons How does access to this work benefit you? Let us know!

\section{Recommended Citation}

Rob, Ubaidur, Md. Noorunnabi Talukder, and A.K.M. Zafar Ullah Khan. 2010. "Future of family planning program in Bangladesh: Issues and challenges," Workshop report. Dhaka: Population Council. 


\title{
Future of Family Planning Program in Bangladesh: Issues and Challenges
}

\author{
Workshop Report
}

\subsection{2.22.2.2.2.2.2.2.2.2.2.2}

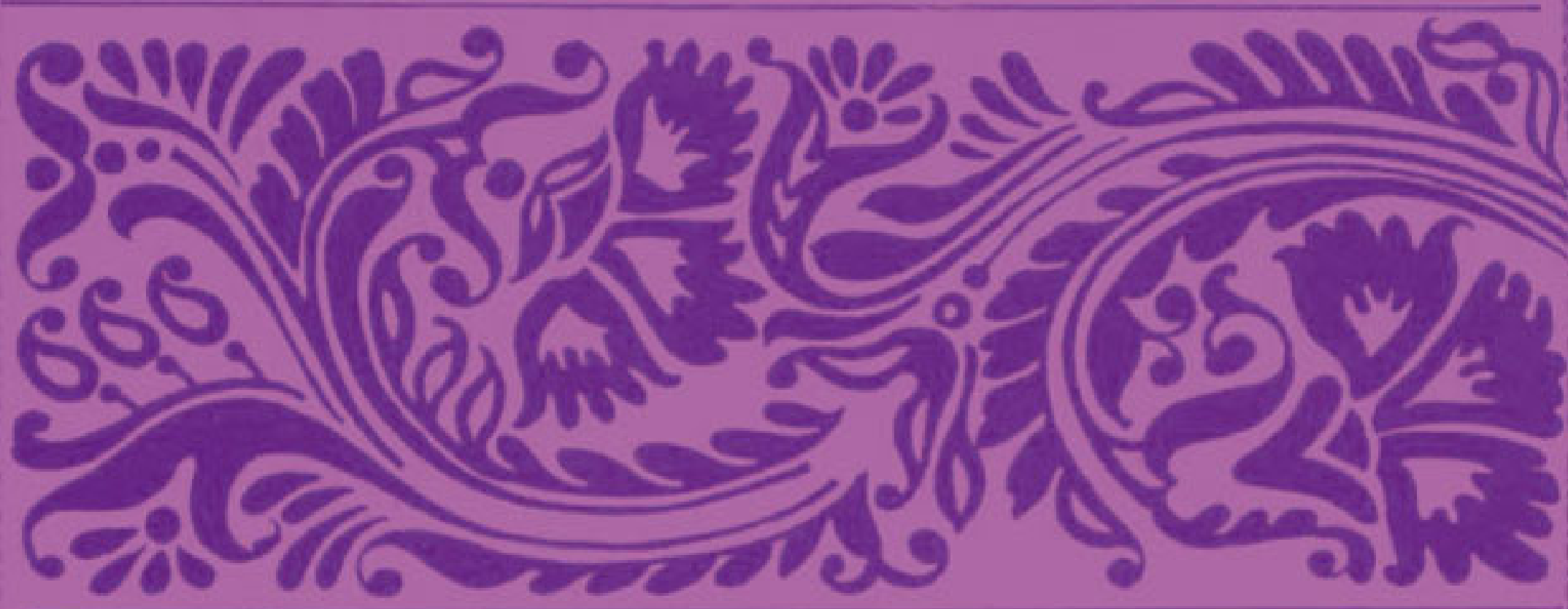

C6.66.66666666666666 


\title{
Future of Family Planning Program in Bangladesh: Issues and Challenges
}

\author{
Workshop Report
}

\author{
Ubaidur Rob \\ Md. Noorunnabi Talukder \\ A.K.M. Zafar Ullah Khan \\ Population Council, Bangladesh
}

October 2010 


\section{CONTENTS}

Acknowledgements $\quad \mathrm{v}$

$\begin{array}{lr}\text { Abbreviations } & \text { vi }\end{array}$

Executive Summary $\quad$ vii

$\begin{array}{ll}\text { I Background } & 1\end{array}$

II Purpose and Organization of the Workshop 1

III Family Planning Program in Bangladesh: Issues and Challenges 3

IV Defining Future Family Planning Program : Stakeholders' Views 7

$\begin{array}{llr}\text { V Way Forward } & 19\end{array}$

Annexure 1 : Program of the Workshop 23

Annexure 2 : List of Workshop Participants 24 


\section{ACKNOWLEDGEMENTS}

The report is an outcome of the workshop on Future of Family Planning Program in Bangladesh: Issues and Challenges organized by the Population Council on 16 October 2010 in Dhaka.

Population Council expresses sincere gratitude to Mr. Md. Humayun Kabir, Secretary, Ministry of Health and Family Welfare, who inaugurated the workshop as the Chief Guest and provided useful direction towards strengthening future family planning program. The Council is also grateful to Ms. Begum Dilruba, Director General of Family Planning, for attending the workshop as the Special Guest. The Council expresses sincere thanks to Dr. Ahmed Al Kabir, President of RTM International for his technical assistance in organizing the workshop.

We are indebted to Dr. A.B.M. Jahangir Alam, Director, Primary Health Care, Directorate General of Health Services, Dr. Jafar Ahmad Hakim, former Director, Maternal and Child Health, Directorate General of Family Planning, Ms. Khadijat Mojidi, Director Health, Population and Nutrition, US Agency for International Development, Dr. Abu Jamil Faisel, Country Representative of Engender Health Bangladesh, Mr. Mohammad Shajahan, Director of Bangladesh Center for Communication Program, Dr. Shehlina Ahmed, Health Adviser to UK Department for International Development, Dr. Barkat E Khuda, Professor, University of Dhaka, and Dr. A.K.M. Nurun Nabi, Professor, University of Dhaka who shared their experiences and particularly provided a platform for useful discussion. We are also thankful to the participants who attended the workshop and provided thoughtful inputs on the subject.

Finally, special thanks are due to Population Council staff members for their sincere efforts in organizing the workshop. 


\section{ABBREVIATIONS}

BCC Behavior Change Communication

CPR Contraceptive Prevalence Rate

DFID Department for International Development

DG Director General

DGFP Directorate General of Family Planning

DGHS Directorate General of Health Services

FWV Family Welfare Visitor

GDP Gross Domestic Product

HFWC Health and Family Welfare Center

IEC Information Education and Communication

IUD Intra-uterine Device

MOHFW Ministry of Health and Family Welfare

NGO Non-Governmental Organization

TFR Total Fertility Rate

UNFPA United Nations Population Fund

USAID US Agency for International Development

VDP Village Defense Party 


\section{EXECUTIVE SUMMARY}

Bangladesh experienced a large growth of population in the past, but due to the success of family planning program, total fertility rate (TFR) declined rapidly until mid-nineties. Over the last decade, the country has been experiencing slow pace in fertility decline with a small increase in contraceptive prevalence rate (CPR). During 1975 to 1994, TFR decreased significantly from 6.3 to 3.3 followed by a period of negligible decline of only 0.6 from 1994 to date. This slow pace in fertility decline is causing serious concern in reaching replacement level fertility by 2015. On the other hand, there is no significant increase in CPR over the period 2000-2009 while CPR increased seven folds during 1975 to 2000, demonstrating the weakness of present program efforts. This raises concern among researchers, policymakers and program managers about the prospect of further reduction in fertility in near future. In this connection, strengthening the national family planning program remains a critical challenge. Against this backdrop, Population Council organized a workshop to find answers to a key question: what opportunities and challenges lie for the family planning program to address future needs.

\section{Challenges to the family planning program}

Several factors slowed the fertility decline in Bangladesh. Demand-side factors that are considered to have influenced the delay in reaching replacement level fertility include:

- Early age at marriage

- Reliance on temporary methods of contraception

- Decline in the use of long-acting and permanent methods

- Discontinuation in the use of contraceptives

- Unmet need for family planning, and

- Regional variation in fertility.

Similarly, there are supply-side concerns related to the family planning program. Shortage of workforce is considered a critical supply-side issue, because of (i) inadequate number of doctors and paramedics, (ii) diminishing family planning workforce, (iii) vacancy of service providers, (iv) absenteeism, and poor accountability of service providers at the field level, and (v) long pause in the training of field-level functionaries. Inadequate, irregular home visit by fieldworkers is one of the reasons for low performance in many areas. Absence of referral system between government and non-government providers is another gap in the service delivery. Yet, there is no structured, sustainable family planning service for urban population. Additionally, there are some programmatic concerns related to the family planning service delivery, which include: uninterrupted supply of contraceptive commodity, inadequate functioning of local-level service delivery points, lapses in the behavior change communication (BCC) activities, and physical infrastructure in remote, hard-toreach areas. 


\section{Recommendations}

As a way forward to equip the future family planning program in Bangladesh, some recommendations prioritized at the workshop are given below.

- Higher demand for children and less accessibility to quality family planning services are accounted for low performance of family planning program in Sylhet and Chittagong divisions. It is necessary to undertake special program in these two low performing divisions; otherwise, the strategies for attaining replacement level fertility will be seriously affected at the national level.

- There is a great problem regarding vacancy of human resources. Under the Directorate General of Family Planning, about 40 percent post of doctors is vacant. The last recruitment of Family Welfare Visitors (FWVs) was in 1996. Filling up the vacant posts of service providers and reviving the training program for FWVs is an important area of immediate attention. To improve field workers' performance and efficiency, financial incentives can be given.

- Inadequate and irregular home visit by fieldworkers is one of the reasons for recent slow increase in contraceptive prevalence rate. Fieldworkers visited more frequently in 1993 than in 2007. The system of accountability, monitoring and supervision is not functioning well. Using community leaders has the potential for monitoring field workforce, as a way to ensure coordination and regularity of services at the community level. At the same time, the ongoing systemic supervision and monitoring needs to be strengthened with necessary manpower.

- Not all clients require special attention at the critical juncture of fertility transition in Bangladesh. High importance should be given to ensure access to family planning services among newly-wed women. Post-partum family planning services is another missed opportunity to which the program should pay immediate attention. Other clients that may need services on priority basis are: low parity couple, low literacy group, and low income group. As aggregate approach has limited impact on further increase in contraceptive prevalence rate, it has been advised to adopt need-based approach for which segmentation of clients is required.

- Government's initiative to introduce vital registration system could be effective to prevent early marriage of girls, if there is social mobilization. Simultaneously, efforts should be underway to sensitize policymakers (Parliamentarians), local-level elected representatives (Upazila Chairman, Union Parishad Chairman), and opinion leaders including teachers, otherwise they will remain insufficiently responsive to the implementation of legal age at marriage and inadequately aware of health risks associated with early marriage of girls.

- There should be a multilayer, multiphase and multiple media campaign, which could utilize the successful experience from recent past. The need to design BCC interventions focusing on demographic characteristics and geographic location is particularly emphasized. It is also necessary to address different target groups through different communication channels. In addition, advocacy and marketing would be critical to design the communication program. 
- Early marriage and early childbearing is ingrained in the culture and specific to the region. This cultural issue should be dealt in a subtle way with particular attention to the existing value system. There should be an effective BCC campaign sensitive to the culture of the region. To undertake the BCC campaign at the community level, community volunteers, women groups, satisfied family planning method acceptors, and community police (Ansar and Village Defense Party or VDP) can be involved.

- Demand-side financing can be initiated to increase the use of long-acting and permanent contraceptive methods. Using the experience or lessons of government's maternal voucher program is a big advantage in this respect. Additionally, the revival of a system of social incentives is badly needed for keeping the family small and for increasing the acceptance of long-acting and permanent methods. Incentive measures may include: preferential treatment in government services, child's admission to school, obtaining bank loan, renewing passport and similar other benefits.

- Extending the route to reach population beyond the Ministry of Health and Family Welfare is found effective. Economic development is critical along with a strong population program. It is, therefore, envisioned to reposition population program as a development concept by linking demographic components with development variables like education, credit, social welfare, livelihood skills etc.

- Reviving the multi-sectoral approach in the population sector has the potential to contribute to further improvement of family planning program in Bangladesh. Ministries other than health need to undertake population activities, which should be reviewed and updated regularly in National Population Council's meetings as was vigorously done in 1980s.

- Waning of political will and commitment contributed to recent slowness of the program. Irregularity of National Population Council meetings is indicative of less priority attached to the population issue by policymakers. The frustration continues as there is missing political will at the local level too. District-level development meeting provides little scope for the family planning to be highlighted, where more than 30 agenda are discussed. It is the strong political will and commitment at both legislative and executive levels that can ensure collaboration within different ministries.

- Redefining the role of NGOs in the family planning sector is urgent. NGO programs are expensive, as only about five percent of the contraceptive prevalence rate is due to NGO activities. A big opportunity lies for the NGOs to concentrate in underserved areas (char, haor and hilly areas) where a few government workers are available and the government is unable to recruit workers either. On the other hand, NGOs have comparative advantage in providing training and conducting BCC activities. The government's program can be supported by those specialized functions of NGOs.

- Due importance must be attached to public-private collaboration. There are large number of private hospitals and clinics. Program managers need to seize the opportunity to provide training on clinical contraception to private providers so that private hospitals and clinics can be an outlet for providing long-acting and permanent methods. As services provided at private facilities are not free, there should be cost-subsidization for low-income clients, 
which can be supported by the government and donors. 'Corporate social responsibility' could be a feasible way for the private sector to support poor clients.

- There is no established referral system between government and non-government providers to provide full range of family planning services, which leaves the opportunity to develop a referral mechanism between public, private and NGO providers.

- Overlapping responsibilities of health and family planning workers is a long-standing problem to the health system in Bangladesh. Both health and family planning fieldworkers visit the same client's house to provide preventive health services and to counsel people on contraceptive methods respectively. At present, there are about 44,500 health and family planning workers, indicating the availability of a fieldworker at each ward in a union. If health-sector field workforce works in coordination with family planning field workforce toward improving the coverage of family planning services at the doorstep, it is likely to help increase contraceptive prevalence rate and reduce fertility. Separate targets can be set for fieldworkers to avoid duplication of visits at the same household.

- In rural areas, first level fixed-facility service is provided at the union level through Health and Family Welfare Centers (HFWC). HFWCs are not utilized optimally, partly due to shortage of service providers (as the client load at HFWC is too high for one female paramedic or FWV to perform her duties efficiently) and inadequate availability of some essential services such as normal delivery, newborn care, and integrated management of childhood illnesses. Additional FWV trained in midwifery is needed for HFWC. The recruitment of an additional FWV cannot be done at the moment, but for future planning this should be considered.

- For the teeming urban slum populations in Bangladesh, there is no structured family planning service. Several NGOs are providing family planning services in limited urban areas, which is, however, subject to the availability of donor assistance. Without any delay, policymakers should consider to develop urban family planning infrastructure with top priority along with the development of necessary guidelines/strategies.

Implementation of these recommendations will require huge investment in the population sector. It is important to note that only three percent of the gross domestic product (GDP) is devoted to the health sector from which less than 20 percent goes to the population sector. No doubt, fund is strictly limited than the actual expenditure. It is imperative that development partners will come forward with assistance and the government will make increased allocation in their regular budget to the family planning program. Along with the increased funding, it is also necessary to ensure program efficiency through optimum use of facilities, infrastructure and personnel.

There is a need to review the current status of programs in the light of future challenges so that the inevitable and irreversible process of demographic transition can be completed and consequently the base population remains relatively small. Broadly, using a combination of three strategies will be useful for designing the future family planning program: (i) strengthen existing program, (ii) utilize elements of successful programs, and (iii) test innovative programs for increased use of family planning services, the results of which might have the relevance for use in efforts to improve service delivery nationally. 


\section{SECTION I: BACKGROUND}

Bangladesh has experienced a large growth of population in the past, but due to the success of family planning program, the total fertility rate (TFR) declined rapidly. Bangladesh had a population of approximately 76 million in 1975 when the TFR was 6.3 children per woman. By 2010, Bangladesh's population had increased to approximately 150 million, and the TFR had fallen to 2.7. Despite the impressive success, Bangladesh's population will grow by 100 million over the next 40 years, reaching 250 million in 2050. A relatively larger proportion of girls will continue to enter into the childbearing age. The impact of population will be reduced if the level of fertility per couple drops below 2 children (replacement level fertility) at a fast pace.

Over the period 2000-2009, Bangladesh has been experiencing slow pace in fertility decline with a small increase in contraceptive prevalence rate (CPR). During 1975 to 1994, TFR decreased significantly from 6.3 to 3.3 followed by a period of negligible decline of only 0.6 from 1994 to date. This slow pace in fertility decline is causing serious concern in reaching replacement level fertility by 2015. On the other hand, there is no significant increase in CPR over the period 2000-2009 while CPR increased seven folds during 1975 to 2000, demonstrating the weakness of recent program efforts. This raises concern among researchers, policymakers and program managers about the prospect of further reduction in the fertility in near future.

Delay in reaching replacement level fertility will stabilize the population at larger size, that is, the challenges of population momentum will be more intense. Within the next 2-3 decades, the number of women in the reproductive age will continue to increase. The extent of increase in the number of women in reproductive age will occur so rapidly that the strategies, in terms of allocations, targets, supplies, logistics, providers, number of one-stop and satellite centers, will need to be updated at regular intervals. In this connection, strengthening the national family planning program remains a critical challenge. Against this backdrop, the Population Council organized a workshop to find answers to a key question: what opportunities and challenges lie for the family planning program to address future needs. This workshop also provided an effective platform to embark upon the program-strengthening process.

\section{SECTION II: PURPOSE AND ORGANIZATION OF THE WORKSHOP}

The goal of the workshop was to identify issues and develop action-oriented future strategies for improving the national family planning program, which would cater the future needs of the population. Specific objectives of the workshop were to:

- Examine present efforts to implement government's commitments to attain replacement level fertility.

- Identify areas of deficiency in the service delivery.

- Identify key demand-side challenges.

- Share the knowledge and practical/policy experience on how national family planning program can be shaped for attaining national demographic goals as well as managing future population. 


\section{Organization of the workshop}

The workshop on "Future of Family Planning Program in Bangladesh: Issues and Challenges" was organized by the Population Council on 16 October 2010 in Dhaka. It was a half-day long workshop and divided into two sessions: keynote paper presentation and thematic discussion. Mr. Md. Humayun Kabir, Secretary, Ministry of Health and Family Welfare (MOHFW), officiated the workshop as the Chief Guest. Ms. Begum Dilruba, Director General of Family Planning was present as the Special Guest. Dr. Ubaidur Rob, Country Director, Population Council Bangladesh presided over the workshop and Mr. A.K.M. Zafar Ullah Khan, Advisor, Population Council and former Secretary, MOHFW moderated the workshop.

In the first session, keynote paper was presented by Dr. Ubaidur Rob. The other session was dedicated to action-oriented discussion, where several designated discussants shared their views on the issue of future family planning program. The workshop ended with the forward-looking speech from the Director General of Family Planning and the Secretary, MOHFW.

The workshop was an apex-level event which brought together key policymakers, program managers, researchers and academicians involved in, and relevant to, the issue of national family planning program. A total of 69 participants attended the workshop. Participants were mostly from the MOHFW, Directorate General of Family Planning (DGFP), and Directorate General of Health Services (DGHS). Participants from academic institutions like University of Dhaka, Jahangirnagar University, BRAC School of Public Health, and American International University Bangladesh joined the workshop. Among others, representatives from development partners, international organizations and non-governmental organizations (NGO) were also present at the workshop. 


\section{SECTION III: FAMILY PLANNING PROGRAM IN BANGLADESH: ISSUES AND CHALLENGES}

The discussion of the inaugural session is summarized in this section. The inaugural session started with the welcome speech of Dr. Ubaidur Rob, Country Director, Population Council. Dr. Rob also presented the keynote paper.

Dr. Rob briefly described the evolution of family planning program in Bangladesh and presented an overview of the current and emerging challenges to 'national family planning program'. Dr. Rob highlighted several demand-side factors that are considered to have influenced the delay in reaching replacement level fertility. He also highlighted several supply-side concerns related to the family planning program and identified gaps in the family planning service delivery.

\section{Early age at marriage}

Dr. Rob expressed concern that minimum legal female age at marriage (18 years) is not observed in the country. More than two-thirds of women are married before their eighteenth birthday and more than half become mother by age 19 . The proportion married has not changed substantially in the last decade - 73 percent in 1989 and 68 percent in 2004. This group contributes approximately one-fifth of the total fertility rate (TFR). Dr. Rob mentioned several compelling demographic reasons for addressing this particular group. The most important one is the size of young population. Approximately 30 million adolescents and youth age 10-24 are living in Bangladesh. The size of this age group will continue to grow in the years ahead due to the population momentum. Dr. Rob stated that delaying adolescent pregnancy can reduce the TFR further, but this will require change in the long-standing culture of social pressure on newly-wed girls to quickly demonstrate their capacity to reproduce. He urged policymakers and program managers to give proper emphasis to this population group.

\section{Reliance on temporary methods of contraception}

Dr. Rob acclaimed the family planning program of Bangladesh, which has contributed to the remarkable increase in the contraceptive prevalence rate (CPR) from 8 percent in 1975 to 56 percent in 2007. He noted that this remarkable achievement is largely due to higher use of temporary methods. In Bangladesh, most of the women rely on temporary methods. Even though three among every ten currently married women have completed their family size and/or have stated that they do not want any more children, the majority of modern method acceptors use oral contraceptives. Dr. Rob considered the imbalance in the method-mix as one of the reasons for the delay in reaching replacement level fertility. He emphasized to ensure rational use of contraceptive methods by pointing out varying needs of a person over the reproductive life cycle.

\section{Decline in the use of long-acting and permanent methods}

Almost 90 percent of women with three or more children have decided not to reproduce any further, while a few of them use long-acting or permanent methods. A decline in the use of longacting and permanent methods except male sterilization has been observed over the last two decades. The use of long-acting and permanent methods reduced from 11 percent in 1993-94 to 7 percent in 2007. Dr. Rob regarded increasing the acceptance of long-acting and permanent methods as a crucial challenge for the future family planning program toward attaining replacement level of fertility. 


\section{Discontinuation in the use of contraceptives}

Dr. Rob considered contraceptive discontinuation as a major obstacle in family planning program. About half of all contraceptive users stop using their chosen method within 12 months of initiation. Discontinuation is high for pills, injectables and condoms. Dr. Rob strongly believed that the discontinuation in the use of contraceptives has clear programmatic implications because these women are not switching but stopping contraceptive use. If discontinuation rate was halved to 25 percent, contraceptive prevalence could be remarkably increased, with no additional effort in user recruitment.

\section{Unmet need for family planning}

Dr. Rob provided an alarming statistics on unmet need for family planning, which has increased from 11 percent in 2004 to 17 percent in 2007. Unmet need for family planning is the highest in Sylhet division (26 percent) followed by Chittagong (23 percent) compared with 12 percent in Rajshahi/Khulna division. Dr. Rob speculated that if the unmet need for family planning could be addressed, current contraceptive prevalence rate would increase enough to achieve replacement level fertility.

\section{Discrepancy between actual and desired fertility}

Dr. Rob also mentioned the discrepancy between actual and wanted fertility. Of the total births, about one-third are mistimed or wanted later. A stark difference between wanted fertility and actual fertility is observed in Sylhet and Chittagong divisions. In these two divisions the gap between wanted fertility and actual fertility is about one child. Dr. Rob drew the attention of policymakers and program managers to the fact that with early marriage and desired low fertility, many women complete their childbearing by mid-late twenties, leaving them two decades of reproductive life to avoid unwanted fertility. Regarding desire for additional children, he said that 63 percent women wanted no more children suggesting a strong demand for family planning, with little variation across regions.

\section{Regional variation in fertility and contraceptive use}

Dr. Rob pointed out the variation in the level of fertility among six geographical regions (i.e., administrative divisions) of Bangladesh despite the small size of the country. Success in reducing fertility was observed in the western part of the country (Khulna and Rajshahi divisions). Khulna division has reached replacement level fertility (TFR: 2) and in Rajshahi TFR is 2.4. Conversely, there is limited achievement in reducing fertility by the eastern part of the country (Sylhet and Chittagong divisions). Dr. Rob expressed his concern about Sylhet and Chittagong divisions, which are lagging far behind than other divisions in reducing fertility with concomitant increase in the contraceptive use. In Sylhet, couples have nearly four children. Similarly, significant regional variation in CPR is also observed. CPR remains substantially low in Sylhet and Chittagong divisions. For example, contraceptive use in Sylhet is half of Khulna (32 percent vs. 63 percent).

Higher demand for children and the weaknesses in health and family planning program are accounted for low performance of Sylhet and Chittagong divisions as assumed by Dr. Rob. In particular, less accessibility to quality family planning services in these regions remains to be a major challenge. Dr. Rob called for immediate attention of policymakers and program managers to these low performing divisions; otherwise the strategies for attaining replacement level fertility will be seriously affected. 


\section{Sources of modern contraceptive methods}

Dr. Rob informed that the largest source of contraceptive supply in Bangladesh is the public sector (50 percent) followed by the private sector (38 percent), while NGOs provide 5 percent of the contraceptive supply. He also highlighted changes in the sources of modern contraceptive methods. Public sector contribution in contraceptive supply was 74 percent in 1996-97 which decreased to 50 percent in 2007. Decrease in the public sector contribution in contraceptive supply has been complemented by the increase in the private sector contribution, which increased from 15 percent to 38 percent during 1997 to 2007 period.

Public sector is the predominant source for long-acting and permanent methods and it, according to Dr. Rob, will continue to play a major role in ensuring free-of-cost provision of quality clinical contraceptive services. On the other hand, private sector is the predominant source for pills and condoms. Dr. Rob suggested using the private sector in a way of counseling and referring the temporary method acceptors (who have completed their family size) for long-acting and permanent methods.

\section{Mobilization of human resource}

Dr. Rob prioritized the vacancy of service providers as the key human resources problem in the family planning sector. Inadequate number of service providers and fieldworkers is another problem of the family planning program. There is the problem of absenteeism, and poor accountability of service providers at the field level.

Dr. Rob elaborated on the complexities related to field workforce. Fieldworkers are aging and new fieldworkers are not being recruited for a long time. The lack of skilled fieldworkers leads to weak functioning of referral for long-acting and permanent methods and side-effects management. There is an urgent need for replenishment of staff who will retire. For increasing the use of long-acting and permanent methods, the need for adequate number of skilled providers is also accentuated in Dr. Rob's keynote speech.

\section{Accessibility and referral}

Dr. Rob noted that inadequate and irregular home visit by fieldworkers is one of the reasons for recent slow increase in the contraceptive prevalence rate. Fieldworkers visited more frequently in 1993 than in 2007. He also mentioned the variation in the visits of fieldworkers across divisions. Sylhet and Chittagong divisions have experienced less number of visits. Nevertheless, Dr. Rob reiterated the importance of fieldworkers for the public-sector community-based family planning service delivery system.

There is no established referral system between government and non-government providers to provide full range of family planning services. Dr. Rob underlined the need to develop a referral mechanism between public, private and NGO providers.

\section{Urban family planning services}

In Bangladesh, the growth in the number of slums as well as slum populations has increased markedly in recent years. Currently, urban population is made up of one-third of slum population, and slum population is growing at twice the rate ( $7 \%$ annually) compared to the overall urban growth rate $(3.5 \%$ annually). For these teeming slum populations, there is no structured family planning service. Several NGOs are providing family planning services in limited urban areas. 
Without any delay, policymakers should consider to improve the urban family planning infrastructure with top priority.

Additionally, Dr. Rob highlighted some other major concerns related to the family planning program, which include: lapses in the behavior change communication (BCC) activities, bottlenecks in service delivery system, future needs of contraceptive commodities, and physical infrastructure in remote, hard-to-reach areas

Finally, Dr. Rob urged to develop a long-term strategic document for future family planning program of Bangladesh, with specific attention to infrastructure, human resources, logistics, BCC and marketing, sustainability, and research and evaluation. 


\section{SECTION IV: DEFINING FUTURE FAMILY PLANNING PROGRAM: STAKEHOLDERS' VIEWS}

The thematic discussion of the workshop is summarized in this section. Mr. A.K.M. Zafar Ullah Khan, advisor to Population Council and former Secretary, MOHFW moderated the thematic discussion session. Broadly, the discussion was divided into two parts: one is demand-side barriers, and the other is supply-side barriers and issues. In this action-oriented discussion session, several designated discussants, from government and non-government sectors, shared their experiences and provided thoughtful inputs on the subject, which laid a platform for useful discussion.

\section{Views of designated discussants}

\section{Mobilizing community and involving multiple actors}

Dr. Ahmed Al Kabir, President of RTM International centered his discussion on involving multiple actors to address the challenges to family planning program.

To begin with, Dr. Kabir pointed out the inadequacy in the implementation of the law on age at marriage. He, however, noted that government's commitment toward a vital registration system could be an effective tool to prevent early marriage of girls, for which social mobilization is necessitated. He substantiated that parliamentarians, local-level elected representatives (Upazila Chairman, Union Parishad Chairman), and opinion leaders including teachers are yet to be sufficiently responsive to the implementation of legal age at marriage, and they are inadequately aware of health risks associated with early age at marriage of girls. Moreover, he expressed frustration on the frailty of current social campaign, which slowed the improvement of the family planning situation in the country. At this point, he underscored the importance of a BCC program that promotes social mobilization where local-level elected representatives and community leaders can be involved. In addition to the social mobilization on age at marriage and family planning, there should be an effective media campaign sensitive to the culture of specific region.

Another recommendation by Dr. Kabir was to develop special activities targeting adolescents and youth through multi-sectoral programs with other ministries and departments, which would be both cost-effective and expansive enough to overcome future challenges of these population groups.

Dr. Kabir was skeptic about the potential of demand-side financing approach. Initiating voucher or any intervention in the demand side for increasing the acceptance of long-acting and permanent methods would not be effective and sustainable if skilled and motivated human resources are not available. Lack of service providers at community clinic and union level may impede the family planning service delivery, particularly of injectables, implants or intrauterine device (IUD). Demandside approach, therefore, cannot be implemented in isolation; it will require all components of health system function in synchronization. At the end of his deliberation, Dr. Kabir recommended effective partnership with NGO and private sector at the upazila level and below to address challenges to family planning program. 


\section{Repositioning population program by linking development components}

Ms. Khadijat Mojidi, Director, Health, Population and Nutrition, USAID in her speech primarily gave emphasis on policy development issues. She appreciated the long-standing, strong political will of the Government of Bangladesh from the policy making to grassroots level contributing to the family planning program.

Ms. Mojidi advised to extend the route to reach the population beyond the MOHFW in a way to use channels other than MOHFW to poise the society through effective population activities. For revitalizing future family planning program, she suggested not only to consider social determinants related to the population sector, but also to consider the determinants that are related to education, status of women, or political commitment. While discussing on communication issues, Ms. Mojidi stressed the need to address different target groups through different communication channels, and highlighted the importance of disseminating culturally appropriate message to the target audience.

She also suggested considering policy dialogues with the other ministries (Ministry of Education, Ministry of Agriculture, Ministry of Information, Ministry of Women Affairs and similar other ministries) and sectors to create a demand and to initiate a focused discussion for a countrywide program. She, thus, envisioned repositioning population program as a development issue by linking demographic components with development variables like education, credit, social welfare, livelihood skills etc.

Ms. Khadijat Mojidi assured that the US Government is willing to work across the sectors and interested in undertaking a two-pronged approach, focusing on population advocacy and family planning service delivery.

\section{Strengthening post-partum family planning}

Dr. Abu Jamil Faisel, Country Representative of Engender Health Bangladesh mentioned two action points in his speech. One of which is the unmet need for family planning, which has been increasing. Dr. Faisel mentioned that every year two million births occur in Bangladesh, while not all these births are desired. He suggested for timely identification and registration of all pregnant women. Identifying and addressing the needs of pregnant women will serve two purposes: decreasing maternal deaths, and providing post-partum family planning for avoiding unexpected pregnancies.

Secondly, Dr. Faisel urged the Directorate General of Health Services to take more responsibilities related to pregnancy and delivery care, i.e., providing post-partum family planning along with the existing services. Health-sector workers need to deliver post-partum family planning services along with the family planning workers in an attempt to expedite further reduction in fertility. Dr. Faisel concluded his speech by expressing similar idea like Ms. Khadijat Mojidi for holding dialogues with ministries other than 'health'. 


\section{Designing client-responsive communication strategy}

Mr. Mohammad Shahjahan, Director, Bangladesh Center for Communication Program, asserted that communication cannot function in vacuum. Like other capacity building activities in the family planning sector (building capacity of facilities, program managers, service providers and stakeholders), it is also important to develop communication capacity, which is missing in the existing program.

Early marriage and early childbearing is ingrained in the culture and specific to the region. Mr. Shahjahan cautioned to deal with this cultural issue in a subtle way with particular attention to the existing value system. To design program for the young people, Mr. Shahjahan put forward a twopronged approach: to provide livelihood opportunities with life skills education, and to make service delivery system friendly to attract youth to receive services. While addressing the issue related to regional variation, it is necessary to look into the perspective at the micro level, i.e., to understand target population. Mr. Shahjahan advised to undertake formative research to know the views and needs of target populations.

To reduce discontinuation of contraceptives and increase the use of long-acting and permanent methods, the attitude of both the prospective acceptor and the provider is important as felt by Mr. Shahjahan. In addition, the quality of services is important. Hence, capacity of service providers in interpersonal communication and counseling has to be taken into account.

Finally, Mr. Shajahan made three recommendations. First, there should be a multilayer, multiphase and multiple media campaign, which could utilize the elements of successful past programs, since it is well known what works and what does not. His second recommendation was to design a campaign which will: (i) make family planning a community norm by enabling the society and different segments of the audience to contribute to the program; and (ii) ensure informed choice as well as cater the needs of individuals according to their life cycle. For designing such communication program, advocacy and marketing would be critical. Finally, Mr. Shahjahan recommended utilizing existing resources with the purpose to cater the needs of low performing regions and also other pockets.

\section{Using opportunities to overcome challenges}

Dr. Shehlina Ahmed, Health Adviser, DFID focused more on opportunities than barriers to the family planning program. Dr. Ahmed highlighted on four areas of opportunities. To begin with, she suggested initiating demand-side financing to increase the use of modern contraceptive methods. Using the experience or lessons of government's maternal voucher program is a big advantage in this respect. Her second recommendation was to revive the system of social incentives for keeping the family small and for increasing the acceptance of long-acting and permanent contraceptive methods. Incentive measures may include: preferential treatment in government services, child's admission to school, obtaining bank loan, renewing passports and similar other benefits. Thirdly, Dr. Ahmed underlined the need to design BCC interventions focusing on both demographic characteristics and geographic location. To design such interventions, it is necessary to identify the opportunity a married woman has in terms of her knowledge of family planning, access to family planning information and services, social network and so on. 
Physical communication is poor on the eastern side of the country. There are many areas in Chittagong and Sylhet divisions that are difficult to reach. Dr. Ahmed emphasized on multi-sectoral approach, particularly the use of information technology to define the problems related to physical accessibility in providing family planning services in hard-to-reach areas.

\section{Harnessing supply-side opportunities}

Dr. Barkat E Khuda, Professor of Economics, University of Dhaka centered his discussion primarily on different supply-side opportunities in the family planning program of Bangladesh. Professor Khuda stated that supply creates its own demand, and demand and supply are interdependent, inseparable. He viewed the family planning program in terms of two phases from supply-side perspective. In the first phase of Bangladesh's Family Planning Program, the thrust was on ensuring supply, e.g., providing full range of modern contraceptive methods, which resulted in the remarkable increase in contraceptive prevalence rate. In the second phase of the program, supply is not the important factor alone while economic development is critical along with the supply factor.

Professor Khuda expressed his concern with current population program by pointing to the lack of political will and commitment. The first and foremost concern is the less priority attached to the population issues by policymakers, which is reflected in the irregularity of meetings of the National Population Council. Further, he raised serious concerns regarding sustainability of the program by mentioning high discontinuation rate of contraceptives, decline in the use of long-acting and permanent methods, and rising unmet need for family planning (17 percent). However, Professor Khuda considered unmet need as an opportunity for the program. In his opinion, couples who are using traditional methods of contraception ( 8 percent) have unmet need for modern methods. That means, the country has 25 percent (actual 17\% plus implied 8\%) unmet need for family planning, which reflects a huge demand. Professor Khuda urged the program managers to pay immediate attention to address the unmet need for family planning so that the program will be able to raise contraceptive use within a short time and couples will have desired fertility as well.

In 2008, a comprehensive National Communication Strategy was developed, which is yet to be implemented as mentioned by Professor Khuda. He further mentioned the challenge related to contraceptive commodity. Contraceptive security remains a major problem as there is the problem of stock-out of long-acting methods and injectables.

On funding issue, Professor Khuda mentioned that only three percent of gross domestic product (GDP) is devoted to the health sector from which less than 20 percent goes to the population sector. No doubt, fund is strictly limited than the actual expenditure. Along with the increased funding, it is also necessary to ensure program efficiency through optimum use of facilities, infrastructure and personnel.

Redefining the role of NGOs in the family planning sector is urgent as strongly advocated by Professor Khuda. NGO programs are expensive while only about five percent of the contraceptive prevalence rate is due to NGO activities. A big opportunity lies for the NGOs to concentrate in underserved areas where the government is unable to recruit workers as commented by Professor Khuda. At the public sector, the process of recruitment and training of field workforce requires a long time. In between, there will be millions of new populations to serve. On the other hand, NGOs 
have comparative advantage in providing training and conducting BCC activities. The government's program can be supported by those specialized functions of NGOs.

Professor Khuda gave importance on public-private collaboration. There are large number of private hospitals and clinics. He urged the program managers to seize the opportunity to provide training on clinical contraception to private providers so that private hospitals and clinics can be an outlet for providing long-acting and permanent methods. Professor Khuda also discussed on possible ways of recovering cost for services provided at private facilities. He suggested for cost-subsidization for low-income clients, which can be supported by the government and donors. Furthermore, 'corporate social responsibility' could be a feasible way for the private sector to support poor clients. To conclude, Professor Khuda emphasized collaboration within different ministries, which can be achieved through sound political will and commitment at the highest level.

\section{Population as a development concept}

Dr. A.K.M. Nurun Nabi, Professor of Population Sciences, University of Dhaka broadened the population concept beyond family planning and promoted population as a development concept, where family planning is a vehicle towards development. Yet, family planning is a strong element for the completion of demographic transition for which both demand and supply side conditions must be fulfilled. Professor Nabi mentioned that there was adequate innovation on supply which created demand and resulted in the reduction in fertility, particularly in 1970s and 80s. Previously, family planning program of Bangladesh was considered as a role model for other developing countries. But this momentum did not continue in the recent past. Professor Nabi stated that paradigm-shift in mid-nineties made the family planning program an orphan. Since then, a period of inadequate attention by the government and development partners on the family planning program follows. Professor Nabi urged for renewed commitment from policymakers, program managers, and development partners.

On adolescent fertility, Professor Nabi felt the necessity to create demand through different channels to delay age at marriage of female adolescents and delay first birth among young couples, which will serve two purposes: reducing the risk of maternal deaths among adolescent girls, and decreasing fertility with increased empowerment. Professor Nabi provided an interesting example of delaying age at marriage among a disadvantaged population group, without any program inputs. He noted that total fertility rate of female garment workers is 1.7 and their average age at marriage is 22.5, which is due to the environment, particularly livelihood opportunities, they are attached to. This indicates that change in behavior does not depend on the communication strategy or media campaign alone, the contextual factors matter. Professor Nabi emphasized on both economic development and demand creation.

Professor Nabi strongly advocated for making population issue as management and planning issue rather a family planning issue. It is important to manage and plan for the future population before the country achieves replacement level fertility. Professor Nabi urged all to work in collaboration as family planning is related to several sectors of development. 


\section{Repositioning human resources strategy}

Dr. A.B.M. Jahangir Alam, Director of Primary Health Care, DGHS has mainly discussed few cardinal points on supply side of the government program. At the beginning of his speech, Dr. Alam underlined to ensure access to family planning and maternal health services among newly-wed girls. Multi-sectoral program efforts are required to address three issues that impel early marriage in rural areas, as Dr. Alam pointed out: physical/social insecurity of keeping girls at home, low literacy rate, and lack of empowerment. Reaching poor with services is a critical area that requires immediate attention too. Post-partum family planning services is another missed opportunity which the MOHFW should take advantage of.

Dr. Alam elaborated on the overlapping of responsibilities of field workforce. Health worker provides preventive health services at client's doorstep while family planning worker visits the same house to counsel people on contraceptive methods. At the union level and below, the MOHFW has adequate human resource as reported by Dr. Alam. At present, there are 44,500 health and family planning workers, indicating the availability of a fieldworker at each ward in a union. He suggested finding out the way to best use these human resources for both health and family planning services. Dr. Alam also observed that recent recruitment and posting of graduate doctors at the union level without creating enabling environment is counter-productive. As there is no accommodation at the union level, these newly recruited doctors either opt for providing services at Upazilla Health Complex or do not come to the periphery at all. It is necessary to develop a practical strategy so that these doctors become interested to serve at the union-level facility.

Regarding urban family planning services, Dr. Alam called for better coordination between Ministry of Local Government and NGOs for ensuring access to family planning services for burgeoning slum population. Similarly, he emphasized partnership with NGOs to serve the population in hardto-reach areas like char and hilly areas, where a few government workers are available.

\section{Ensuring availability of human resources at the field level}

Dr. Jafar Ahmad Hakim, former Director, MCH, DGFP mentioned that there is a great problem regarding vacancy of human resources. Under the Family Planning Directorate, about 40 percent post of doctors is vacant, which needs to be filled up immediately. Further, there should be a defined promotion channel and carrier planning in order to retain doctors under the Family Planning Directorate. Dr. Hakim also mentioned that the last recruitment of Family Welfare Visitors (FWVs) was in 1996. It is urgent for the program to recruit FWVs, and train and post them immediately.

In rural areas, first level fixed-facility service is provided at the union level through Health and Family Welfare Centers (HFWC). Traditionally, HFWC is the main source for maternal health check-ups and child health services. Dr. Hakim expressed concerns regarding the underutilization of HFWCs, which is partly due to shortage of service providers (as the client load at HFWC is too high for one FWV to perform her duties efficiently) and inadequate availability of some essential services such as normal delivery, newborn care, and integrated management of childhood illnesses. Dr. Hakim strongly advocated for strengthening HFWCs with necessary human resources and equipments to provide normal delivery and newborn care services. He emphasized the need for an additional FWV trained in midwifery for HFWC. The recruitment of an additional FWV cannot be done at the moment, but for future planning this should be considered. 
Dr. Hakim underscored the need to strengthen coordination and collaboration between the Ministry of Health and Family Welfare and the Ministry of Local Government in a way to improve urban family planning services. Priority should be attached to the family planning services that will cater the need of the slum population, who are mostly deprived of services.

Finally, Dr. Hakim urged the policymakers and program managers to go for urgent and quick implementation of the major recommendations made in the workshop.

\section{Developing urban strategy}

Mr. Dhiraj Kumar Nath, former Adviser to the Caretaker Government of Bangladesh elaborated on the needs and priorities of urban family planning services and underlined the necessity to develop an 'urban strategy'.

No policy or strategy is in place for providing primary health care and family planning services to urban population. Mr. Nath urged the government to develop an Urban Health and Family Planning Strategy, which would (i) improve the health status of urban population with the adoption of small family norm, (ii) encourage the acceptance of long-acting and permanent methods, (iii) create positive change in the family planning services in urban areas, and (iv) improve the family planning, reproductive health and nutrition status of urban poor.

Mr. Nath mentioned the inadequacy of family planning services in urban areas, which is largely dependent on NGOs. He noted that the Ministry of Local Government is responsible for the primary health care and family planning services in urban areas. Several NGOs are providing primary health care including family planning services in selected urban areas, with limited coverage. These NGO services are subject to the availability of development assistance. Mr. Nath was not in favor of leaving the family planning services to NGOs alone. Instead, he emphasized to expand the reach and coverage of the government program and involve private sector providers. He sketched out several strategies to make the urban family planning service delivery sustainable.

- Review existing system of providing family planning services by NGOs in urban areas.

- Specify roles and responsibilities of multiple organizations (Ministries of Health and Local Government, city corporations, municipalities, NGOs, private clinics) in providing family planning services.

- Provide services through infrastructure development.

- Ensure private-public partnership for training, quality assurance, BCC and marketing.

- Institutionalize referral system.

- Generate awareness for small family norm and enhance community participation.

- Make family planning services in urban areas accessible, affordable and sustainable with depot holders.

Mr. Nath strongly recommended improving urban family planning services as thrust sector by mobilizing resources. Strategic policy reforms that are required to make the family planning service delivery sustainable include: 
- Ensure political commitment.

- Develop organizational infrastructure.

- National health, population and nutrition policies to provide guidelines.

- Institutional development for sustainability.

Mr. Nath concluded his speech by making four recommendations.

- It is necessary to establish a new "Ministry on Urban Development". Urban population is growing rapidly and half of the total population will live in cities and municipalities within next 20-30 years, which demands a separate Ministry to address health, population and human development issues.

- National Committee headed by the Minister Local Government and Rural Development should be constituted to provide guidelines and monitor the service delivery system.

- Urban health and family planning services need to be improved as thrust sector mobilizing resources and manpower.

- Urban family planning needs to be addressed independently, not as part of health care.

\section{Open discussion}

After the thematic discussion, there was an open discussion where the following comments were made.

Dr. M.A. Mabud, former Division Chief, Planning Commission, expressed his worry over the huge vacancy under Family Planning Directorate. He suggested that doorstep services should be strengthened to decrease the discontinuation rate of family planning methods. He strongly advocated for reviving of multi-sectoral approach in the population sector by pointing out the contribution of multi-sectoral projects/programs to the earlier success of family planning program in Bangladesh. Until 1998, the population sector activities were conducted by several ministries, which worked under one umbrella - National Population Council. Dr. Mabud acclaimed the implementation of strong multi-sectoral approach of population activities in 1980s by noting that National Population Council's meeting was held every two months during that period. He suggested forming a 'division' within MOHFW for dealing with population activities. Dr. Mabud commented that the full potential of NGOs has not been reaped for family planning services.

Dr. Mabud promoted the concept of 'population management' instead of population control at the critical juncture of fertility transition in Bangladesh. Managing the huge population on small landscape will be the major responsibility of the current and future governments. Livelihood opportunities for young population in the country and mobility of people beyond the national boundary need to be increased through human resource development. Dr. Mabud opined that there should be a human resource policy to transform the demographic transition into an economic transition. 
Dr. Ahmed Neaz, Professor, American International University Bangladesh, gave importance on the segmentation of clients. Dr. Neaz noted that the government field workforce remained the same while clients increased nearly double which makes difficult for the workforce to cover the increased population. He proposed to cover only selected clients instead of all clients since aggregate approach is likely to have limited impact on further increase in the contraceptive prevalence rate. Clients that may need services on priority basis are: clients living in low performing areas, low parity couple, young couple, low literacy group, and low income group. Dr. Neaz advised to adopt need-based approach for which segmentation of clients is required.

Dr. Neaz strongly believed that family planning in the context of Bangladesh is still important. It is to be noted that the thrust of the family planning program has waned since the government adopted broader reproductive health paradigm, under which family planning is a small component. The program performance deteriorated which can be partly reflected in the small decline of total fertility rate. Still, a strong family planning program is needed in Bangladesh as there is high unmet need for family planning which is substantiated with high discontinuation rate of family planning methods, large number of unwanted births, and undesirable pregnancies that result in abortion. By referring the gap between family planning desire and practice of clients, Dr. Neaz placed emphasis on the regularity in worker-client contact. It is also necessary to empower clients to transform them from passive receiver of services at a domiciliary level to an active seeker of services from facilities or service delivery points.

Dr. Syed Jahangir Haidar, Director, READ mentioned a successful example of the community mobilization in resisting early marriage in rural areas. It is the 'community police' that persuades parents and social leaders not to allow early marriage, thus resist early marriage at the community level. Similarly, there is opportunity for other sectors to prevent early marriage. Regarding demand creation, Dr. Haidar commented that Family Planning Directorate is not capable of handling the broad range of information, education and communication (IEC) activities at its disposal. Instead, IEC should have specific focus. It would be more useful if the directorate concentrated on the domiciliary or community level communication program with the purpose to transform the desired family size into actual family size.

Dr. Haidar expressed frustration over the missing political will at the local level. District-level development meeting provides little scope for the family planning to be highlighted, where more than 30 agenda are discussed.

Professor Kazi Saleh Ahmed, former Vice Chancellor, Jahangirnagar University, highlighted two issues: multi-sectoral approach and regional variation. Professor Ahmed commented that age at marriage will not increase through the single focus on family planning service as he reasoned that age at marriage is largely dependent on employment. By realizing the need to develop mechanism of linking employment with population activities, Professor Ahmed strongly advocated for an integrated approach where other ministries will be involved to achieve a common goal of increasing the age at marriage of girls. Particularly, he called for developing a broad development model by integrating multiple ministries; otherwise, it will not be possible for the family planning program to achieve its demographic goals. Regarding regional variation, Professor Ahmed provided an optimistic picture. He mentioned that Sylhet is better than many other districts if haor and hilly areas of Sylhet are not considered. He, therefore, necessitated to redesigning the program for the region with special inputs to hard-to-reach areas. 
Dr. Hashina Begum, Assistant Representative, UNFPA highlighted several issues on the demand generation and the use of local-level service delivery points. Dr. Begum is not complacent with the effectiveness of BCC activities in providing accurate and complete information (how to use, sideeffects, effective duration of methods) on family planning methods although knowledge on the name of family planning methods is almost universal among eligible couples. She recommended that BCC needs to be in-depth and marketing should be in place. At the supply side, Dr. Begum justified the need to strengthen the supervision and monitoring, which would in turn ensure whether the workforce provides the information and services adequately, and whether there is optimum utilization of services from facilities.

Using satellite clinic for family planning services was considered as a missed opportunity by Dr. Begum. She noted that women, who give births recently and come to satellite clinics to receive immunization for their children, are rarely inquired of whether they have any need for family planning services. On the other hand, most people do not know whether satellite clinic provides family planning services.

Another missed opportunity lies with the utilization of union level facility (HFWC) for long-acting and permanent contraceptive services. Dr. Begum urged the program managers to make provision for providing long-acting and permanent methods at the union level facility either through training of medical officer or by conducting camp at the facility by bringing medical officer from the upazila level.

Dr. Tofayel Ahmed, former Director, Management Information System, DGHS recommended to revitalize the system of monitoring service providers regarding the performance on permanent methods as it was done during 1980s. At the community level, there is no deficiency in human resources as there is a large workforce consisting of Family Welfare Assistants and Health Assistants. Dr. Ahmed was optimistic on the idea of setting targets for fieldworkers to avoid duplication of visits at the same household. He speculated that if Health Assistant works in coordination with Family Welfare Assistant toward improving the family planning service at the doorstep, it is likely to help increase CPR and reduce TFR. Dr. Ahmed, however, advised to be cautious while setting targets for Health Assistants.

Dr. Selina Amin, Health Adviser, Plan International also emphasized to strengthen the monitoring system. Dr. Amin recognized the potential of using 'community clinic management group' for local level monitoring system. This group can monitor the activities of Family Welfare Assistants and Health Assistants and thus can ensure coordination and regularity of services provided at the community level. Furthermore, strengthened monitoring system is required for achieving program targets.

Dr. A.K.M. Mahbubur Rahman, Line Director, Clinical Contraception Service Delivery, DGFP advised to undertake innovative approaches on the priority issues identified at the workshop. Dr. Rahman illustrated an innovative approach of increasing male participation in family planning. The initiative was to orient 30 satisfied sterilized male clients from each Upazila to advise potential acceptors, which resulted in increased acceptance of male sterilization. 
Professor M.A. Wahab, former Dean, School of Education, Bangladesh Open University, suggested using the education sector to create awareness among school-going children. Issues like legal age marriage and immunization can be included in the textbook curriculum.

Dr. Sharmin Sultana, Quality Assurance and Training Specialist, RTM International, brought forth the issue regarding lack of capacity of field-level managers, providers and workers to understand the indicators of family planning and health or to calculate rate and ratios. Dr. Sultana suggested to train field-level functionaries on indictors and to include this subject into the training program at the national level.

Mr. Taslim Uddin Khan, Head, Research and Evaluation, Social Marketing Corporation, advocated for involving the private sector to provide long-term and permanent methods. Mr. Khan appreciated the role of the private sector in increasing the use of contraceptive methods. He informed that large portion of the increase in CPR is from temporary methods, which is contributed mainly by the private sector. In contrast, there is no contribution from the private sector to longacting and permanent methods. Public-private partnership is necessary to address low use of longacting and permanent methods. Private sector needs to extend their collaboration while the government should give the policy support for making enabling environment.

\section{Speech of DG, Family Planning}

Ms. Begum Dilruba, Director General (DG), Family Planning highlighted several recent government commitments directed towards increasing CPR for attaining replacement level fertility. The DG identified several priority areas for immediate attention to improve the family planning service delivery:

- Address regional differences in TFR through special efforts in low performing and hard-toreach areas.

- Increase acceptance of long-acting and permanent family planning methods with male participation.

- Reduce discontinuation of contraceptives.

- Encourage delayed marriage and delayed first birth among young couples.

- Reduce high unmet need for family planning.

- Adopt need-based approach through segmentation of clients.

- Develop sustainable urban family planning service delivery.

The DG was supportive of reviving the multi-sectoral approach for population activities. She also stated that there is opportunity for public-private collaboration in providing long-acting and permanent family planning methods. Similarly, partnership with NGOs is required to serve the population in hard-to-reach areas like char and hilly areas, where a few government workers are available. The DG requested the Population Council to present the workshop recommendations in a structured way to the concerned authority for further improvement of the family planning program. 


\section{Speech of the Secretary, MOHFW}

Mr. Md. Humayun Kabir, Secretary, MOHFW congratulated the Population Council for organizing the workshop at the appropriate time, which focused on the current and future challenges to the family planning program of the country. The Secretary mentioned that the past decades have seen a remarkable increase in population programs, but not implemented in a coordinated fashion. There was some duplication of efforts. The secretary advised to maximize the use of limited resources and address the actual needs of the population. He emphasized three issues that need urgent attention as a way to strengthen family planning program: (i) strengthen service delivery system, (ii) ensure coordination between the program implementers, and (ii) rationalize the field-level workforce.

The MOHFW has a streamlined population control program, but the ministry will be facing the challenge of reaching country's large population as well as delaying age at marriage. The Secretary was of the opinion that ensuring legal age at marriage needs an innovative approach for which other ministries should also be involved. Moreover, future population programs and plans need to center on the need of increased number of women in the reproductive age. Regarding urban population, the Secretary elaborated that MOHFW visualizes health as a sectoral approach and it intends to incorporate urban health strategy as a component of next health sector program. He also emphasized to address family planning along with urban health.

The Secretary attached high importance to address the pressing challenges to the family planning program for realizing Vision 2021. He concluded with the pledge that the Ministry of Health and Family Welfare will continue the momentum of the current program efforts and incorporate the recommendations from this workshop in the next sector program. 


\section{SECTION V: WAY FORWARD}

Family planning in the context of Bangladesh is still important. It is to be noted that the thrust of the family planning program has waned since the government adopted broader reproductive health paradigm in mid-90s, under which family planning is a small component. Still, a strong family planning program is needed in Bangladesh since there is no significant increase in contraceptive prevalence rate over the last decade and there is a high unmet need for family planning along with high discontinuation rate of contraceptive methods. Persistent reliance on temporary methods of contraception and decline in the use of long-acting and permanent methods is another key concern of current family planning program. As a way forward to improve the performance of family planning services, it has been derived from the workshop that political commitment is the first and foremost requirement to address the issues of immediate concerns. Specific recommendations as prioritized at the workshop are as follows:

- Higher demand for children and the weaknesses in service delivery are accounted for low performance of family planning program in Sylhet and Chittagong divisions. In particular, less accessibility to quality family planning services in these regions remains a major challenge. It is necessary to undertake special program in these two low performing divisions; otherwise, the strategies for attaining replacement level fertility will be seriously affected at the national level.

- While addressing the issue related to regional variation, it is necessary to look into the perspective at the micro level, i.e., to understand target population. Prior to design interventions, it is necessary to identify the opportunity a married woman has in terms of her knowledge of family planning, access to family planning information and services, social network and so on. At the same time, there should be mapping to identify constraints and opportunities in low performing and hard-to-reach areas for improving program performance.

- There is a great problem regarding vacancy of human resources. Under DGFP, about 40 percent post of doctors is vacant. The last recruitment of female paramedics (FWVs) was in 1996. Filling up the vacant posts of service providers and reviving the training program for FWVs is an important area of immediate attention. To improve field workers' performance and efficiency, financial incentives can be given.

- Inadequate and irregular home visit by fieldworkers is one of the reasons for recent slow increase in contraceptive prevalence rate. Fieldworkers visited more frequently in 1993 than in 2007. The system of accountability, monitoring and supervision is not functioning well. Using community leaders has the potential for monitoring field workforce, as a way to ensure coordination and regularity of services at the community level. At the same time, the ongoing systemic supervision and monitoring needs to be strengthened with necessary manpower.

- Not all clients require special attention at the critical juncture of fertility transition in Bangladesh. High importance should be given to ensure access to family planning services among newly-wed women. Post-partum family planning services is another missed opportunity to which the program should pay immediate attention. Other clients that may 
need services on priority basis are: low parity couple, low literacy group, and low income group. As aggregate approach has limited impact on further increase in contraceptive prevalence rate, it has been advised to adopt need-based approach for which segmentation of clients is required.

- Government's initiative to introduce vital registration system could be effective to prevent early marriage of girls, if there is social mobilization. Simultaneously, efforts should be underway to sensitize policymakers (Parliamentarians), local-level elected representatives (Upazila Chairman, Union Parishad Chairman), and opinion leaders including teachers, otherwise they will remain insufficiently responsive to the implementation of legal age at marriage and inadequately aware of health risks associated with early marriage of girls.

- There should be a multilayer, multiphase and multiple media campaign, which could utilize the successful experience from recent past. The need to design BCC interventions focusing on demographic characteristics and geographic location is particularly emphasized. It is also necessary to address different target groups through different communication channels. In addition, advocacy and marketing would be critical to design the communication program.

- Early marriage and early childbearing is ingrained in the culture and specific to the region. This cultural issue should be dealt in a subtle way with particular attention to the existing value system. There should be an effective BCC campaign sensitive to the culture of the region. To undertake the BCC campaign at the community level, community volunteers, women groups, satisfied family planning method acceptors, and community police (Ansar and Village Defense Party or VDP) can be involved.

- Demand-side financing can be initiated to increase the use of long-acting and permanent contraceptive methods. Using the experience or lessons of government's maternal voucher program is a big advantage in this respect. Initiating voucher or any intervention in the demand side for increasing the acceptance of long-acting and permanent methods would be effective and sustainable if skilled and motivated human resources are available.

- The revival of a system of social incentives is badly needed for keeping the family small and for increasing acceptance of long-acting and permanent contraceptive methods. Incentive measures may include: preferential treatment in government services, child's admission to school, obtaining bank loan, renewing passport and similar other benefits.

- Extending the route to reach population beyond the MOHFW is found effective. Economic development is critical along with a strong population program. It is, therefore, envisioned to reposition population program as a development concept by linking demographic components with development variables like education, credit, social welfare, livelihood skills etc.

- Reviving the multi-sectoral approach in the population sector has the potential to contribute to further improvement of family planning program in Bangladesh. Ministries other than health need to undertake population activities, which should be reviewed and 
updated regularly in National Population Council's meetings as was vigorously done in 1980s.

- Waning of political will and commitment contributed to recent slowness of the program. Irregularity of National Population Council meetings is indicative of less priority attached to the population issues by policymakers. The frustration continues as there is missing political will at the local level too. District-level development meeting provides little scope for the family planning to be highlighted, where a large number of agenda are discussed. It is the strong political will and commitment at both legislative and executive levels that can ensure collaboration within different ministries.

- Developing special activities targeting adolescents and youth through multi-sectoral programs with other ministries and departments is critical, which would be both costeffective and expansive enough to empower these population groups through employment creation. To design program for young people, a two-pronged approach might be useful: provide livelihood opportunities with life skills education, and to make service delivery system friendly to attract youth to receive services.

- Redefining the role of NGOs in the family planning sector is urgent. NGO programs are expensive, as only about five percent of the contraceptive prevalence rate is due to NGO activities. A big opportunity lies for the NGOs to concentrate in underserved areas (char, haor and hilly areas) where a few government workers are available and the government is unable to recruit workers either. On the other hand, NGOs have comparative advantage in providing training and conducting BCC activities. The government's program can be supported by those specialized functions of NGOs.

- Due importance must be attached to public-private collaboration. There are large number of private hospitals and clinics. Program managers need to seize the opportunity to provide training on clinical contraception to private providers so that private hospitals and clinics can be an outlet for providing long-acting and permanent methods. As services provided at private facilities are not free, there should be cost-subsidization for low-income clients, which can be supported by the government and donors. 'Corporate social responsibility' could be a feasible way for the private sector to support poor clients.

- There is no established referral system between government and non-government providers to provide full range of family planning services, which leaves the opportunity to develop a referral mechanism between public, private and NGO providers.

- Overlapping responsibilities of health and family planning workers is a long-standing problem to the health system in Bangladesh. Both health and family planning fieldworkers visit the same client's house to provide preventive health services and to counsel people on contraceptive methods respectively. At present, there are 44,500 health and family planning workers, indicating the availability of a fieldworker at each ward in a union. If health-sector field workforce works in coordination with family planning field workforce toward improving the coverage of family planning services at the doorstep, it is likely to help increase contraceptive prevalence rate and reduce the fertility. Separate targets can be set for fieldworkers to avoid duplication of visits at the same household. 
- Recent recruitment and posting of graduate doctors at the union level without creating enabling environment is found counter-productive. As there is no accommodation at the union level, these newly recruited doctors either opt for providing services at Upazila Health Complex or do not come to the periphery at all. It is necessary to develop a practical strategy so that these doctors become interested to serve at the union level facility. Furthermore, there should be a defined promotion channel and career planning in order to retain doctors.

- In rural areas, first level fixed-facility service is provided at the union level through Health and Family Welfare Centers (HFWC). HFWCs are not utilized optimally, partly due to shortage of service providers (as the client load at HFWC is too high for one female paramedic to perform her duties efficiently) and inadequate availability of some essential services such as normal delivery, newborn care, and integrated management of childhood illnesses. Additional FWV trained in midwifery is needed for HFWC. The recruitment of an additional FWV cannot be done at the moment, but for future planning this should be considered.

- Using satellite clinic is an opportunity to reach women, who give births recently and come to satellite clinics to receive immunization for their children, with the family planning counseling and short-term modern methods. For long-acting and permanent contraceptive services, it is necessary to strengthen family planning activities at the union level facility (HFWC) either through training of medical officer or by conducting camp at the facility by bringing medical officer from the upazila level.

- For the teeming urban slum populations in Bangladesh, there is no structured family planning service. Several NGOs are providing family planning services in limited urban areas, which is, however, subject to the availability of donor assistance. Without any delay, policymakers should consider to develop the urban family planning infrastructure with top priority along with the development of necessary guidelines/strategies.

Implementation of these recommendations will require huge investment in the population sector. It is important to note that only three percent of GDP is devoted to the health sector from which less than 20 percent goes to the population sector. No doubt, fund is strictly limited than the actual expenditure. It is imperative that development partners will come forward with assistance and the government will make increased allocation in their regular budget to the family planning program. Along with the increased funding, it is also necessary to ensure program efficiency through optimum use of facilities, infrastructure and personnel.

There is a need to review the current status of programs in the light of future challenges so that the inevitable and irreversible process of demographic transition can be completed and consequently the base population remains relatively small. Broadly, using a combination of three strategies will be useful for designing the future family planning program: (i) strengthen existing program, (ii) utilize elements of successful programs, and (iii) test innovative programs for increased use of family planning services, the results of which might have the relevance for use in efforts to improve service delivery nationally. 


\title{
ANNEXURE 1 \\ Program of the Workshop
}

\author{
"Future of Family Planning Program in Bangladesh: Issues and Challenges" \\ Venue: BRAC Center Inn, Mohakhali, Dhaka \\ Date: 16 October 2010
}

\begin{tabular}{|c|c|}
\hline $9: 30 \mathrm{am}-10: 00 \mathrm{am}$ & Registration \\
\hline $\begin{array}{ll}\text { Chief Guest: } & \mathbf{M} \\
\text { Special Guest: } & \mathbf{B c} \\
\text { Chair: } & \mathbf{U l}\end{array}$ & $\begin{array}{l}\text { Md. Humayun Kabir, Secretary, Ministry of Health and Family Welfare } \\
\text { Begum Dilruba, Director General, DGFP } \\
\text { Ubaidur Rob, Country Director, Population Council }\end{array}$ \\
\hline 10:00 am - 10:05 am & Recitation from the Holy Quran \\
\hline 10:05 am - 10:30 am & 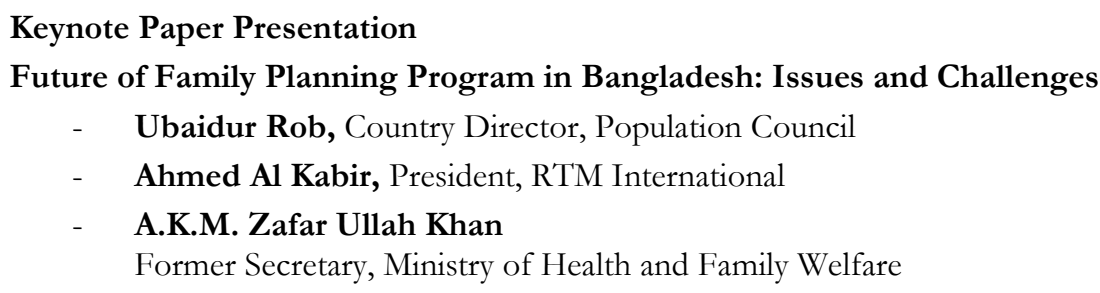 \\
\hline $10: 30 \mathrm{am}-11: 00 \mathrm{am}$ & Tea \\
\hline \multirow{3}{*}{$11: 00 \mathrm{am}-12: 30 \mathrm{pm}$} & $\begin{array}{l}\text { Thematic Discussion } \\
\text { Moderator: A.K.M. Zafar Ullah Khan }\end{array}$ \\
\hline & $\begin{array}{l}\text { Demand-side barriers/issues: } \\
\text { - Early age at marriage and early child bearing } \\
\text { - } \text { Regional variation in desired family size and fertility } \\
\text { - Decline in the use of long-acting and permanent methods } \\
\text { - Discontinuation in the use of family planning methods }\end{array}$ \\
\hline & $\begin{array}{l}\text { Supply-side barriers/issues: } \\
\text { - Unmet need for family planning } \\
\text { - Regional variations in utilization of services } \\
\text { - Mobilization and capacity building of human resource } \\
\text { - Urban family planning services } \\
\text { - Service delivery/ Facility strengthening }\end{array}$ \\
\hline \multirow{3}{*}{$12: 30 \mathrm{pm}-1: 00 \mathrm{pm}$} & Remarks by the Special Guest \\
\hline & Remarks by the Chief Guest \\
\hline & Closing Remarks by the Chair \\
\hline \multicolumn{2}{|r|}{ Lunch } \\
\hline
\end{tabular}




\section{ANNEXURE 2}

\section{List of Workshop Participants}

(Not According to Seniority)

1. Mr. Md. Humayun Kabir, Secretary, MOHFW

2. Mr. Abu Taher, Joint Secretary, MOHFW

3. Dr. A.B.M. Jahangir Alam, Director, PHC \& Line Director, ESD, DGHS

4. Ms. Begum Dilruba, Director General, DGFP

5. Dr. A.K.M. Mahbubur Rahman, Line Director, CCSD, DGFP

6. Dr. Md. Zane Alam, Program Manager, CCSD, DGFP

7. Dr. S.A. Fida Hasan, Program Manager, Field Service Delivery, DGFP

8. Ms. Hosne Ara Begum, Director, Planning, DGFP

9. Dr. Tapash Ranjan Das, Deputy Director, MCH, Program Manager, MHS, DGFP

10. Mr. Mohammad Zearul Islam, Deputy Director, IEM, DGFP

11. Ms. Ratna Talukder, Deputy Director, IEM, DGFP

12. Mr. Rezaul Islam, Deputy Director, MIS, DGFP

13. Mr. Md. Rokon Uddin, Asst. Director (Coordination), DGFP

14. Dr. Fahmida Sultana, Asst. Director, MCH, DGFP

15. Ms. Shirin Afroze, NIPORT

16. Dr. Sharifa Begum, Sr. Res. Fellow, BIDS

17. Ms. Khadijat L. Mojidi, Director, PHN Office, USAID

18. Mr. Marcos Arevalo, Family Planning Advisor, USAID

19. Dr. Shehlina Ahmed, Health Adviser, DFID

20. Dr. Hashina Begum, Assistant Representative, UNFPA

21. Mr. Aminul Arefin, Technical Officer, M\&E/Research ,UNFPA

22. Mr. Habibur Rahman, Senior Program Manager, KFW Office

23. Dr. Abu Jamil Faisel, Country Representative, Engender Health

24. Dr. Shabnam Shahnaz, Country Representative, Pathfinder International

25. Dr. Selina Amin, Health Adviser, Plan International

26. Dr. S.M. Shahidullah, Project Manager, Plan International

27. Dr. Fadia Sultana, Program Manager, Save the Children, USA

28. Mr. Nazmul Kabir, Deputy Program Manager, Save the Children, USA

29. Dr. M.H. Chowdhury, General Manager (Services), Marie Stopes Clinic Society

30. Mr. Latifur Rahman, PDO, Marie Stopes Clinic Society

31. Mr. Mohammad Shahjahan, Director, BCCP

32. Dr. Farhana Ahmad, National Coordinator, White Ribbon Alliance, Bangladesh

33. Dr. Arefin Amal Islam, Health Officer, Smiling Sun Franchise Program

34. Mr. Taslim Uddin Khan, Head, Research \& Evaluation, SMC

35. Dr. Syed Jahangir Haider, Executive Director, READ

36. Ms. Rokeya Sultana, Training Specialist, CWFD

37. Dr. S. M. Mohiuddin Kamal, Executive Director, RADDA MCH-FP Centre 
38. Professor Barkat E Khuda, Department of Economics, University of Dhaka

39. Professor A.K.M. Nurun Nabi, Department of Population Sciences, University of Dhaka

40. Professor Kazi Saleh Ahmed, Former Vice Chancellor, Jahangirnagar University

41. Dr. Ahmed Neaz, Professor, AIUB

42. Dr. M.A. Mabud, Former Division Chief, Planning Commission \& President, Organization for Population and Poverty Alleviation

43. Professor M.A. Wahab, Former Dean, School of Education, Bangladesh Open University

44. Dr. Farah Mahjabeen, Senior Lecturer \& Coordinator CEP, JPGSPH, BRAC University

45. Dr. T. Ahmad, MIS, DMCS

46. Mr. Shahin Ahmed, Managing Editor, Shilpakantha

47. Mr. Pronob Kumar Mozumder, PC, VOSD

48. Mr. Rasheed, Independent Consultant

49. Dr. Ahmed Al Kabir, President, RTM International

50. Dr. Sharmin Sultana, QA \& Training Specialist, RTM International

51. Dr. Mustafiza Rushdi, Program Specialist, RTM International

52. Dr. Humaira Begum, Program Officer, RTM International

53. Ms. Selina Zafar, RTM International

54. Mr. Mahbubur Rahman Jewel, Program Assistant, RTM International

55. Dr. Nazrul Islam, Ex-DPM, EOC, DGHS

56. Dr. Jafar Ahmad Hakim, Former Director, MCH, DGFP

57. Mr. Dhiraj Kumar Nath, Former Advisor, Caretaker Government of Bangladesh

58. Dr. Ubaidur Rob, Country Director, Population Council

59. Mr. A.K.M. Zafar Ullah Khan, Advisor, Population Council \& Former Secretary, MOHFW

60. Dr. Sharif Mohammed Ismail Hossain, Associate, Population Council

61. Ms. Laila Rahman, Program Officer, Population Council

62. Dr. Ismat Ara Hena, Program Officer, Population Council

63. Mr. Md. Moshiur Rahman, Program Officer, Population Council

64. Mr. Md. Noorunnabi Talukder, Program Officer, Population Council

65. Mr. Amar Krishna Baidya, Assistant Program Officer, Population Council

66. Mr. Md. Mostafizur Rahman Khan, Senior Research Officer, Population Council

67. Ms. Eshita Jahan, Research Officer, Population Council

68. Ms. Kaji Tamanna Keya, Research Officer, Population Council

69. Ms. Sareeta Haider, Research Officer, Population Council 


\section{Population Council}

wuw.popcouncil.org

South \& East Asia - Bangladesh Office House CES (B) 21, Road 118

Gulshan, Dhaka 1212, Bangladesh

Phone: 8802-8821227, 8826657

Fax: 8802-8823127

Email: info,bangladesh@popcouncil.org 